\title{
The Efficacy of Intra-Muscular Botulinum Toxin A (Btx-A) Injections on Spasticity Reduction in Spastic Cerebral Palsy
}

\author{
Zaid Al Dahamsheh*, Kareem Al Rashdan, Awni Al Hadid, Mohammed Al Bakheet and Emad Al Soub \\ Royal Medical Services, Jordan
}

Received: 制: October 08, 2018; Published: ㄴ-1: October 23, 2018

*Corresponding author: Zaid Al Dahamsheh, Royal Medical Services, Jordan

\begin{abstract}
Introduction: Cerebral palsy (CP) is known as a clinical syndrome that occurs following a breakdown to the motor areas of the immature brain. Therapeutic options include the injection of BTX-A.

Study Objectives: the main objective of the present study is to investigate the impact of BTX-A injection on the spasticity scores of children with CP.

Methods and Subjects: A prospective study design was conducted from January 2017 to June 2018 at Royal Rehabilitation Center. A total of 128 children with CP were included. Children with were treated with BTX-A and followed for 3 and 6 months. At basal level, demographical and clinical data were recorded. Data included age, gender, and spasticity scores. Spasticity scores were determined using Modified Ashworth Scale pre and post injections.
\end{abstract}

Study Results: The age mean was $8.73 \pm 5.70$ years. The score of spasticity at basal level was $3.34 \pm 0.67$, and then it was decreased further after three months follow up and reached $1.27 \pm 0.99$. The spasticity score was further increased to the level of $3.07 \pm 0.86$ after 6 months follow up. There was a significant impact of using single injection of BTX-A on lowering the spasticity score levels after 3 months and 6 months follow up (p<0.001). There were also significant differences in the mean of scores at 3 and 6 months follow up $(p<0.001)$. At basal level, males have significantly increased levels spasticity scores compared with females ( $\mathrm{p}=0.002)$. At 3 and 6 months follow up, no significant differences were attributed to gender ( $p>0.05)$.

Conclusion: The study findings showed that single doses of ABT-X has therapeutic effects in decreasing the levels of spasticity scores.

Keywords: Cerebral Palsy; Spasticity; Spasticity Scores; ABTX-A; Modified Ashworth Scale

\section{Introduction}

Cerebral palsy (CP) is known as a clinical syndrome which is not progressive from one side, and that occur following a breakdown to the motor areas of the immature brain [1-3]. CP is the most prevalent entity leading to physical disability in children with incidence of 2 to 2.5 per 1000 live births [4]. Most children with CP have clinical symptoms of spastic paresis, a muscle-tone and muscle control-regulation disorder [5]. Spasticity is regarded as the chief participating variable in the functional altering and lowering the growth of longitudinal muscle inspastic CP children [6]. Lowering spasticity can be achieved through several therapeutic options among which is the injection of botulinum toxin type A (BTX-A), that is considered as effective and safe [7].
The mechanism of action of BTX-A depends on a manner of dosedependent and it is reversible chemodenervation of the injected muscle through the blocking of presynaptic release of acetylcholine [8]. Wang and Gao [9] conducted a study about the use of botulinum toxin A (BTX-A) that is used to treat children with spastic cerebral palsy. The duration of its injection is limited for short periods, which requires multiple injections. The authors aimed to assess the impacts and safety measures of multiple injections of BTX-A in children with spastic cerebral palsy. The results showed that the use of BTX-A was beneficial after one week of the injection, and side effects were noted within one week of injections. Taken together, BTX-A improved muscle tone significantly in 3 and 6 months after serial injections compared with baseline $(p<0.05)$ 
Study Objectives: the main objective of the present study is to investigate the impact of BTX-A injection on the spasticity scores of children with CP.

\section{Methods and Subjects \\ Study Design and Setting}

A prospective study design was conducted from January 2017 to June 2018 at Royal Rehabilitation Center.

\section{Study Sample}

A total of 128 children with CP were included in the study.

\section{Study Procedure}

After the study had been approved by ethical committee of Royal Medical Services, researchers started the practical steps in conducting the study. Children with $\mathrm{CP}$ who were undergoing the treatment with BTX-A were followed for 3 and 6 months. At basal level, demographical and clinical data were recorded. Data included age, gender, and spasticity scores. Spasticity scores were determined using Modified Ashworth Scale pre and post injections. Dysport (AbobotulinumtoxinA, 500 IU per vial; Ipsen Ldt, Slough, UK) was used in this study. The dose range varied between 5-30 U/ $\mathrm{Kg} / \mathrm{BW}$, with a maximum dose of $500 \mathrm{U}$ Per patient. and was given according to the manufacturer's instructions.

\section{Statistical Analysis}

All data obtained were entered into excel sheet for each patient. After the data had been completely entered into excel sheet, the data were entered into SPSS version 21 for statistical analysis. Two modes of descriptive analysis, frequency and percentages for categorical variables such as gender, and means and standard deviations for continuous variables such as age, and spasticity scores were used to present data. The relationships between variables were computed based on paired sample $\mathrm{T}$ test, dependent and independent. The significance was considered at alpha $<0.05$.

\section{Results}

As shown in Table 1, the study included a total of 128 children with CP of whom, the most proportion (71.1\%) was for males. The age mean was $8.73 \pm 5.70$ years. The score of spasticity at basal level was $3.34 \pm 0.67$, and then it was decreased further after three months follow up and reached $1.27 \pm 0.99$. The spasticity score was further increased to the level of $3.07 \pm 0.86$ after 6 months follow up.

Table 1: General characteristics of study participants.

\begin{tabular}{|c|c|}
\hline Variable & Description \\
\hline Gender: (N, \%) & $91(71.1 \%)$ \\
Male & $37(28.9 \%)$ \\
Female & $8.73 \pm 5.70$ \\
\hline Age (M \pm SD) years & $3.34 \pm 0.67$ \\
\hline Spasticity (M \pm SD): & $1.27 \pm 0.99$ \\
Basal level & $3.07 \pm 0.86$ \\
3 months & \\
6 months & \\
\hline
\end{tabular}

\section{The Impact of BTX-A on Spasticity Scores}

As seen in Table 2, there was a significant impact of using single injection of BTX-A on lowering the spasticity score levels after 3 months, and 6 months follow up $(p<0.001)$. There were also significant differences in the mean of scores at 3 and 6 months follow up $(\mathrm{p}<0.001)$.

Table 2: The impact of BTX-A on spasticity scores (using paired T test).

\begin{tabular}{|c|c|c|}
\hline Spasticity levels & M \pm SD & Significance \\
\hline Basal level & $3.33 \pm 0.67$ & $<0.001$ \\
3 months & $1.27 \pm 0.99$ & $<0.001$ \\
\hline Basal level & $3.33 \pm 0.67$ & \\
6 months & $3.07 \pm 0.86$ & $<0.001$ \\
\hline 3 months & $1.27 \pm 0.99$ & \\
6 months & $3.07 \pm 0.86$ & \\
\hline
\end{tabular}

\section{The Impact of Gender on Spasticity Scores}

We investigated if the gender may have impacts on the scores of spasticity following the injection of BTX-A. At basal level, males have significantly increased levels spasticity scores compared with females $(p=0.002)$. At 3 and 6 months follow up, no significant differences were attributed to gender $(\mathrm{p}>0.05)$ (Table 3$)$.

Table 3: The impact of gender on spasticity scores (using independent T-test).

\begin{tabular}{|c|c|c|}
\hline Spasticity levels & $\mathbf{M} \pm \mathbf{S D}$ & Significance \\
\hline Basal level: & $3.52 \pm 0.57$ & 0.002 \\
Male & $2.93 \pm 0.79$ & \\
Female & $1.27 \pm 0.99$ & 0.576 \\
\hline After 3 months: & $1.13 \pm 0.97$ & \\
Male & $2.87 \pm 1.00$ & 0.118 \\
Female & $3.08 \pm 0.60$ & \\
\hline After 6 months: & & \\
Males & & \\
\hline
\end{tabular}

\section{Discussion}

The main objective of this study was to explore the effect of injections of BTX-A on lowering the spasticity scores among children with CP. The data of the present study showed that there was a significant impact of using single injection of BTX-A on lowering the spasticity score levels after 3 months, and 6 months follow up $(\mathrm{p}<0.001)$. This finding is consistent with other studies that indicated to improved spasticity scores as a result of treatment with BTX-A [10-12].

We investigated if the gender may have impacts on the scores of spasticity following the injection of BTX-A. At basal level, males have significantly increased levels spasticity scores compared with females ( $p=0.002)$. At 3 and 6 months follow up, no significant differences were attributed to gender ( $p>0.05)$. Our data agree with other studies in which gender has no effect on the following up of spasticity scores $[13,14]$. 


\section{Conclusion}

The study findings showed that single doses of ABT-X has therapeutic effects in decreasing the levels of spasticity scores.

\section{References}

1. Gormley ME, Gaebler-Spira D, Delgado MR (2001) Use of botulinum toxin type A in pediatric patients with cerebral palsy: A three-center retrospective chart review. J Child Neurol 16(2): 113-118.

2. EunSook Park, Dong-wook Rha (2006) Botulinum Toxin Type A Injection for Management of Upper Limb Spasticity in Children with Cerebral Palsy: A Literature Review. Yonsei Medical Journal 47(5): 589-603.

3. Friedman BC, Goldman RD (2011) Use of botulinum toxin A in management of children with cerebral palsy. Canadian Family Physician 57(9): 1006-1073.

4. Stanley F, Blair E, Alberman E (2000) Clinic in developmental medicine. No 151. London, UK: Mac Keith Press. Cerebral palsies: Epidemiology and causal pathways p. 22-39.

5. Beckung E, Carlsson G, Carlsdotter S, Uvebrant P (2007) The natural history of gross motor development in children with cerebral palsy aged 1 to 15 years. Dev Med Child Neurol 49(10): 751-756.

6. Dunne JW, Heye N, Dunne SL (1995) Treatment of chronic limb spasticity with botulinum toxin A. J Neurol Neurosurg Psychiatry 58(2): 232-235.

7. Mohamed KA, Moore AP, Rosenbloom L (2001) Adverse events following repeated injections with botulinum toxin A in children with spasticity. Dev Med Child Neurol 43(11): 791.

ISSN: 2574-1241

DOI: $10.26717 / B J S T R .2018 .10 .001922$

Zaid Al Dahamsheh. Biomed J Sci \& Tech Res

(C) (P) This work is licensed under Creative

Commons Attribution 4.0 License

Submission Link: https://biomedres.us/submit-manuscript.php
8. Aoki KR, Guyer B (2001) Botulinum toxin type A and other botulinum toxin serotypes: A comparative review of biochemical and pharmacological actions. Eur J Neurol 8(5): 21-29.

9. Wang YJ, Gao BQ (2013) Efficacy and safety of serial injections of botulinum toxin A in children with spastic cerebral palsy. World J Pediatr 9(4): 342-345.

10. Lee LR, Chuang YD, Yang BJ, Hsu MJ, Liu YH (2004) Botulinum toxin for lower limb spasticity in children with cerebral palsy: A single-blinded trial comparing dilution techniques. Am J Phys Med Rehabil 83(10): 766-773.

11. Scholes VA, Dallmeijer AJ, Knol DL (2006) Combined effect of lower-limb multilevel botulinum toxin type $\mathrm{A}$ and comprehensive rehabilitation on mobility in children with cerebral palsy: A randomized clinical trial. Arch Phys Med Rehabil 87(12): 1551-1558.

12. Bjornson K, Hays R, Graubert C, Price R, Won F, et al. (2007) Botulinum Toxin for Spasticity in Children with Cerebral Palsy: A Comprehensive Evaluation. Pediatrics 120(1): 49-58.

13. Cheung J, Rancourt A, Di Poce S, Levine A, Hoang J, et al. (2015) PatientIdentified Factors That Influence Spasticity in People with Stroke and Multiple Sclerosis Receiving Botulinum Toxin Injection Treatments. Physiotherapy Canada 67(2): 157-166.

14. Reddihough DS, King JA, Coleman GJ (2002) Functional outcome of botulinum toxin A injections to the lower limbs in cerebral palsy. Dev Med Child Neurol 44(12): 820-827.

$\begin{array}{ll}\text { BIOMEDICAL } & \text { Assets of Publishing with us } \\ \text { RESEARCHES } & \text { - Global archiving of articles } \\ \text { - Immediate, unrestricted online access }\end{array}$

